\title{
La crónica en América Latina. El caso de Etiqueta Negra
}

\author{
Recibido: 02 de noviembre de 2014 \\ Aceptado: 30 de junio de 2015 \\ Publicado: 30 de octubre de 2015
}

beata.szady@gmail.com

Universidad de Breslavia (Polonia)

\begin{abstract}
Resumen: A finales del siglo XX, en América Latina, Gabriel García Márquez fundó la Fundación de Nuevo Periodismo Iberoamericano (FNPI). Gracias a esta, unos años después, se logró el crecimiento de los medios, especialmente de las revistas que publican crónicas periodísticas. Uno de los exponentes más importantes de esta vertiente es la publicación peruana Etiqueta Negra. En el presente artículo se detalla la situación de la crónica contemporánea en América Latina y un análisis crítico de Etiqueta Negra.
\end{abstract}

Palabras clave: Periodismo, crónica, América Latina, FNPI, Etiqueta Negra.

Abstract: At the end of the 20th century, in Latin America, Gabriel Garcia Márquez created the Foundation of New Latin American Journalism (FNPI). Thanks to this, a few years later, it shows the growth of the media, especially magazines that published chronicles. One of the most important exponents is the Peruvian magazine Etiqueta Negra. This article details the situation of the contemporary Chronicle in Latin America and a critical analysis of Etiqueta Negra.

Key words: Journalism, Chronicle, Latin America, FNPI, Etiqueta Negra.

\section{Introducción}

En América Latina no se tiene una definición clara de la crónica. Alberto Fuguet, escritor chileno, confiesa que no sabe qué es la crónica, que ni siquiera “distingue entre periodismo y ficción a la hora de escribir, porque finalmente todo para él, incluida su actual veta de cineasta, es parte de una misma obra y de una misma mirada" (ápud Aguilar, 2010: 159). 
Aunque Leila Guerriero (2012b), la cronista argentina, sabe que es la crónica (historia de no ficción que requiere un largo trabajo de campo y que se narra utilizando recursos formales de la literatura de ficción), tiene problemas en clasificar su trabajo: "se supone que lo que yo hago es periodismo narrativo. Pero para mi todo esto de clasificación, que la crónica, que el periodismo narrativo, no sé” (ápud Jalil, 2010: 38).

Quizá una de las definiciones más llamativas sobre la crónica es la del mexicano Juan Villoro (2012: 578-579), quien asegura que esta pieza periodística es el "ornitorrinco de la prosa", porque toma rasgos de distintos géneros:

"De la novela extrae la condición subjetiva, la capacidad de narrar desde el mundo de los personajes y crear una ilusión de vida para situar al lector en el centro de los hechos; del reportaje, los datos inmodificables; del cuento, el sentido dramático en espacio corto y la sugerencia de que la realidad ocurre para contar un relato deliberado, con un final que lo justifica; de la entrevista, los diálogos; y del teatro moderno, la forma de montarlos; del teatro grecolatino, la polifonía de testigos, los parlamentos entendidos como debate: la voz de proscenio, como la llama Wolfe, versión narrativa de la opinión pública cuyo antecedente fue el coro griego; del ensayo, la posibilidad de argumentar y conectar saberes dispersos; de la autobiografía, el tono memorioso y la reelaboración en primera persona [...] La crónica es un animal cuyo equilibrio biológico depende de no ser como los siete animales distintos que podría ser".

En esa línea, el peruano Julio Villanueva Chang (2012: 598), fundador de la revista Etiqueta Negra, sugiere que la crónica es "un género camaleónico y excéntrico. De allí que Juan Villoro la definiera como el ornitorrinco de la prosa". El venezolano Boris Muñoz (2012: 630) sostiene que si la crónica es como un "ornitorrinco", el cronista se parece más a un murciélago:

"En realidad, los cronistas son los X-Men de la prosa. ¿Por qué? Porque a pesar de ser mamíferos como la mayoría de los animales terrestres -no quiero implicar aquí que la mayoría de los periodistas sean unos animales terrestres, vuela. Volar, en este sentido figurado, significa usar el lenguaje para conferirle a la escritura cierta altivez verbal y un uso de la imaginación que la hacen literaria".

Ornitorrinco, camaleón, murciélago, X-Men... son términos que convergen en torno a la crónica y a los cronistas latinoamericanos. En España, el periodista Miguel Ángel Bastenier habla de la "teoría de marciano", según la cual "se requiere mirar la realidad con ojos de asombro, despiertos, como si fuéramos, precisamente, marcianos que acaban de llegar a la tierra, y todo lo que miráramos fuera desconocido para nosotros" (ápud Fuentes, 2009: 72). El cronista Luis Tejada sentenció su credo personal en El Espectador:

"El mejor cronista es el que sabe encontrar siempre algo de maravilloso en lo cotidiano; el que puede hacer trascendente lo efímero; el que, en fin, logra poner mayor cantidad de eternidad en cada minuto que pasa. El mejor 
periodista no es el más sabio sino el más intuitivo; no es el que escribe mejor sino el que mejor sabe hacer escribir; no es el más honrado, ni el más sincero, sino el que es capaz de hacer decir al mayor número de gentes: ¡eso era lo que yo pensaba!” (ápud Villanueva Chang, 2012: 605).

\section{FNPI}

La crónica, tal como es concebida por los autores mencionados en este trabajo, es un género de reciente data:

"Un tiempo -no tan remoto: 1996, 1997- en el que no existían los llamados cronistas latinoamericanos (ni revistas que los publicaran, ni antologías que los antologaran) y en el que la palabra 'crónica' se usaba, en los países de América Latina, para mentar las más diversas cosas -los despachos urgentes, las notas policiales, las columnas-, pero en pocos o en ninguno designaba lo que hoy se conoce" (Guerriero, 2012b).

A mediados de los noventas, en Cartagena de Indias, surgió la Fundación Nuevo Periodismo Iberoamericano (FNPI), liderado por Gabriel García Márquez, para mejorar la práctica periodística. Se abrieron talleres bajo la guía de los cronistas Alma Guillermoprieto y Tomás Eloy Martínez. A partir del 2001, la Fundación organizó la primera edición del Premio Cemex-FNPI que reconocía las mejores producciones cronísticas de la región.

La FNPI produjo una generación de periodistas que sabían que "lo que hacían no era muy atractivo, pero sospechaban que había una especie de más allá que sí lo era. Los talleres de la fundación mostraban la posibilidad de ese más allá" (ibídem). Con el nuevo milenio surgieron una serie de revistas que se animaron a publicar crónicas y así "dibujaron el mapa aún borroso de un futuro que nadie veía venir" (ibidem). Entre las más importantes figuran las colombianas El Malpensante (1996), SoHo (1999), Gatopardo (2000) y la peruana Etiqueta Negra (2002), lo cual reafirma la tendencia de que la crónica y el periodismo narrativo en general conforman un "género de revistas" (ibídem).

\section{Auge}

La aparición de estas revistas y el surgimiento de foros y premios (tales como "Las Nuevas Plumas", instaurada en el 2010 por la Universidad de Guadalajara en México y la Escuela de Periodismo Portátil, del cronista chileno Juan Pablo Meneses) habrían fomentado un boom de la crónica en América Latina.

"El comentado boom de la crónica en América Latina ya no es una moda. Si se enseña en las universidades; si sus escritores se agrupan, debaten en foros, dictan talleres y se conocen; si varias revistas la incluyen como un ingrediente principal de su contenido, es porque hay un público que espera y pide prensa 
de calidad, rigurosa y que va más allá de lo inmediato" (Fuentes, 2009: 13).

Guerriero (2012b) reúne las apreciaciones de diferentes escritores sobre este fenómeno:

Figura 1: Valoraciones sobre el boom de la crónica latinoamericana.

\begin{tabular}{|l|l|}
\hline $\begin{array}{l}\text { Mario } \\
\text { Jursich }\end{array}$ & $\begin{array}{l}\text { "Hacia } 2003 \text { había conciencia de que la crónica estaba pasando por un momento } \\
\text { de auge, pero la teníamos quienes hacíamos revistas, los practicantes del género } \\
\text { y urupo de lectores pequeño. Es solo ahora que el público general empieza a } \\
\text { darse cuenta de que la crónica está viviendo una época de oro". }\end{array}$ \\
\hline $\begin{array}{l}\text { Jaime } \\
\text { Abello }\end{array}$ & $\begin{array}{l}\text { "En los últimos } 15 \text { años se han creado revistas, no se ha parado de producir } \\
\text { crónica, y empezaron a publicarse más libros. Pero aunque la crónica ha ganado } \\
\text { más mercado, sigue siendo de nicho". }\end{array}$ \\
\hline $\begin{array}{l}\text { Guillermo } \\
\text { Osorno }\end{array}$ & $\begin{array}{l}\text { "¿Sabes para mí qué sería el signo inequívoco del boom? Sentarme con las patas } \\
\text { encima de mi escritorio a esperar a que lleguen a mi cuenta de correo textos } \\
\text { arrebatadores, después de que los autores estuvieron con toda calma investigando } \\
\text { sus temas, y poder pagar lo justo por esos textos". }\end{array}$ \\
\hline $\begin{array}{l}\text { Margarita } \\
\text { García } \\
\text { Robayo }\end{array}$ & $\begin{array}{l}\text { "Si hay un boom se restringe a gente que escribe periodismo, y que los buenos } \\
\text { siguen siendo los de siempre. No hay mucho recambio". }\end{array}$ \\
\hline $\begin{array}{l}\text { Juan } \\
\text { Pablo } \\
\text { Meneses }\end{array}$ & $\begin{array}{l}\text { "En el Premio 'Las Nuevas Plumas' hemos recibido más de trescientas crónicas } \\
\text { inéditas [...] Ahí está el auge. El financiamiento, el sitio donde publicarlas, el } \\
\text { pago, puede ser un fracaso, pero no tiene que ver con la esencia de contar una } \\
\text { historia real, sino con la parte administrativa”. }\end{array}$ \\
\hline
\end{tabular}

Fuente: Elaboración propia.

Esa dimensión "administrativa" provoca que muchos cronistas busquen otros trabajos para poder subsistir y hacer más sostenible la labor de la escritura. El editor adjunto de Etiqueta Negra y ganador del Premio Las Nuevas Plumas del 2011, Eliezer Budasoff(2014) remarca lo anterior:

"Creo que nadie puede vivir exclusivamente de escribir las crónicas. Yo siempre hacía montón de cosas que me permitieran escribir la crónica, es decir trabajaba para comprarme el tiempo necesario para escribir las crónicas. Incluso los grandes cronistas, como Alberto Salcedo Ramos, hacen lo mismo".

Los cronistas y los editores son concientes de los problemas que experimentan dentro del competitivo mercado laboral latinoamericano: poco espacio para publicar, falta del pago por los textos, poco tiraje, que los obliga a contar con otras fuentes de ingresos para poder sobrevivir. Los periodistas y narradores son conscientes que para poder escribir tienen que retar, buscar otros espacios (comerciales) para la crónica y otras alternativas para que la crónica no languidezca. Guerriero (2012a: 620) recoge ese sentir en el siguiente extracto:

"Es raro, entonces, que se hable, como se habla, del auge de la crónica 
latinoamericana.

Principalmente porque pocos medios gráficos, salvo las honrosas excepciones que todos conocemos, están dispuestos a pagarle a un periodista para que ocupe dos o tres meses de su vida investigando y escribiendo sobre un tema. Siguiendo porque los editores suelen funcionar con un combustible que se llama urgencia y con el que la crónica suele no llevarse bien. Y finalmente, y quizás sobre todo, porque pocos medios están dispuestos a dedicarle espacio a un texto largo ya que, se supone -lo dicen los editores, lo vocean los anunciantes, lo repiten todos-, los lectores ya no leen.

Y sin embargo, sin medios donde publicarla, sin medios dispuestos a pagarla y sin editores dispuestos a darles a los periodistas el tiempo necesario para escribirla, se habla hoy de un auge arrasador de la crónica latinoamericana".

\section{Etiqueta Negra}

Es una revista de periodicidad mensual que circula en el Perú desde el 2002. Su fundador y editor, Julio Villanueva Chang, es un cronista conocido en el medio local y en la región latinoamericana. Es autor de Mariposas y murciélagos (1999) y Elogios criminales (2009) y De cerca nadie es normal (2014) comenta lo siguiente:

"Es una revista que siempre he tratado de definir por vía negativa, es decir, por lo que no es. En ese sentido, no es una revista de autoayuda; en lugar de aconsejar, lo que queremos es desengañar. $\mathrm{Y}$ tampoco es una revista estrictamente periodística ni una revista de literatura, porque no publicamos cuentos ni poemas ni adelantos de novelas. Nos hemos dedicado a lo que en el mundo anglosajón se llama non-fiction. Publicamos crónicas, perfiles, testimonios, viñetas, ensayos. No somos una revista de entretenimiento; más que divertir, queremos distraer, pero distraer en el sentido que Octavio Paz le daba a esta palabra. Él decía: "Distracción quiere decir atracción por el reverso de este mundo" (ápud CAF y FNPI, 2006: 144).

No hay duda de que Etiqueta Negra es una revista cultural. Jorge Herralde, editor de Anagrama (España) afirmar que es "una de las mejores y más singulares revistas culturales en lengua española" (Etiqueta Negra, núm. 32: 15). Como una "revista de culto", exhibe crónicas, perfiles, testimonios, viñetas, ensayos de los cronistas más importantes de América Latina (Martín Caparrós, Leila Guerriero, Juan Villoro, Alma Guillermoprieto) y del resto del mundo (Jon Lee Anderson, Ryszard Kapuściński, Susan Orlean). A modo de manifiesto, que refleja el espíritu de la revista, Villanueva Chang arguye:

"Personalmente tengo una contienda contra toda esa casta de periodistas que creen que lo periodístico sólo es corrupción, guerra y miseria, y que lo demás no es periodístico sino que es publicidad o es banal, o es frívolo o es inofensivo. Creo que hay toda una tradición de revistas como The New Yorker, The Atlantic, Harper's, que han demostrado que se pueden hacer grandes 
historias de acontecimientos que a primera vista y a primer oído no le interesan a nadie o no le interesarían a los periodistas. Y ese es un problema. Creo que los periodistas a veces terminamos haciendo revistas para periodistas, medios para periodistas, o tratando a los lectores como si fueran periodistas. $Y$ creemos que un medio es mejor que otro cuando hay periodistas de cierto prestigio a quienes les gusta, les parece duro, les parece extraordinario, golpeador. Sólo hay que recordar que ni todo el periodismo que cubre historias de corrupción, guerra, finanzas y miseria es necesariamente bueno; ni todo el periodismo que cubre otro tipo de historias es necesariamente banal, frívolo o inofensivo" (ápud CAF y FNPI, 2006: 148-149).

Como una manera de rescatar las cualidades expuestas en el extracto anterior, David Fischman (Etiqueta Negra, núm. 2: 7), una de las plumas colaboradoras de la revista, subraya lo siguiente:

"Según Kouzes y Posner, el primer paso del liderazgo es romper lo establecido y eso es lo que ha logrado el equipo de ETIQUETA NEGRA. Es una nueva categoría de revista. Su mayor ruptura de esquemas es que el periodismo no tiene que decidirse a destapar escándalos, encontrar culpables o simplemente sacar nuestros instintos bajos para vender".

\subsection{Desengañar}

Villanueva Chang emplea reiteradamente un verbo que define Etiqueta Negra, desengañar:

"A veces, el cronista solo intenta decir mejor que nadie lo que todo el mundo piensa; otras veces el cronista escribe contra lo que casi todo el mundo piensa. Una crónica no es tanto un estilo de narrar sino de mirar la realidad, un intento de darle sentido al caos traduciéndolo a una historia. En una crónica, más que denunciar, se trata de desengañar. Convertir el dato en conocimiento y, en lo posible, un acontecimiento en experiencia" (ápud Simonetti, 2010): 274).

Según Albert Szent-Györgyi, "el descubrimiento consiste en ver lo que todos han visto, pero pensar lo que nadie ha pensado". Esto implica desengañar y así se escriben los textos para Etiqueta Negra (ápud Villanueva Chang, 2012: 591).

\subsection{La más bella}

El valor de esta publicación reside tanto en su contenido como en su parte visual. Un buen diseño y calidad de papel, con un nivel artístico altísimo, hacen que su centenar de páginas la conviertan en un producto exclusivo. Según Juan Villoro, Etiqueta Negra combina "las mejores virtudes del nuevo periodismo. Una revista versátil, con gran diseño y un ojo 
avizor por la actualidad que no rehúye los temas profundos" (Etiqueta Negra, núm. 32: 52). En el 2013, el diario italiano La Repubblica consideró a Etiqueta Negra como una de las revistas de considerable estética y originalidad del orbe:

"Etiqueta Negra es un éxito editorial gracias a sus autores excepcionales, a una edición extenuante hasta la perfección y a la convicción de que no ha llegado el fin de la prensa escrita. Sólo depende de lo que en ella se escribe" (Etiqueta Negra, núm. 115: 47).

\subsection{Los textos}

\subsubsection{La idea}

En el caso de la escritura de Etiqueta Negra, el elemento creativo más importante es la idea, no el tema. La idea tiene que universalizar la historia. Villanueva Chang (2014) lo explica de la siguiente forma:

"Si alguien me dice que quiere escribir algo sobre la quinua, para mí no vale. Es el tema, pero ¿de qué trata esta historia? Yo tengo que saber qué es importante en la quinua para el autor. De qué exactamente quiere escribir. A mí me interesa siempre preguntar de qué trata la historia. Lo importante es que la experiencia de un individuo sirva para explicar la historia universal de millones de personas. Esto es el credo esencial para convertir un tema".

\subsubsection{La longitud}

En este tipo de revistas, las crónicas gozan de libertad en cantidad y extensión. Lo más preciado es la calidad. Daniel Samper Ospina, director de $\mathrm{SoHo}$, dedica 40 páginas para los proyectos de largo aliento, como el perfil de cantante de vallenatos Diomedes Díaz, realizado por Alberto Salcedo Ramos ( $c f$. Guerriero, 2012b). Budasoff (2014) nos cuenta el proceso de composición en Etiqueta Negra:

"Cuando estaba editando mi crónica, cuando en algunos momentos me pedían las cosas, yo sabía que mi texto esta creciendo. Y estuve preocupado, sin razón, por extensión. Eso es maravilloso: escribir sin el pensamiento de que tienes que cortar. No tienes otros lugares donde puedes hacer eso".

En Etiqueta Negra, los textos alcanzan en promedio las 20 páginas, pero no todos son largos. El criterio no es solamente la longitud, sino la calidad. Budasoff (2014) comenta que si el texto tiene 6 mil palabras y le sobran 4 mil, se publica con 2 mil. La idea es que todo lo esta publicado tenga un sentido orgánico y que no se publique sólo por publicar. 


\subsubsection{Una pregunta}

Los subtítulos de los textos están planteados de manera interrogativa. Con la pregunta se busca exponer la idea general del texto. Por ejemplo: "Un amante de las estatuas. ¿Cuál es el encanto de un hombre de bronce?" (Etiqueta Negra, núm. 106), "Slim, un mecenas que usa calculadora. ¿Puede el hombre más rico del mundo ser una buena persona?” (Etiqueta Negra, núm. 117), "Lo que ellos ven. ¿Por qué un ciego tiene la cortesía de pagar el recibo de la luz?” (Etiqueta Negra, núm. 116). Villanueva Chang apuntala:

"Debajo del título, necesito un subtítulo. Siempre es una pregunta. A veces la pareja de ambos es muy sencilla y, más que una idea, solo define un tema. 'El ABC del señor K: ¿Qué lee un corresponsal de guerra antes de subirse a otro avión?' [...] A veces, la pareja es más compleja y permite entrever cierta idea del personaje: 'Un extraterrestre en la cocina. ¿Cuántos platos debe romper un cocinero para convertirse en el chef más revolucionario del planeta?'. Si el título es el anzuelo, el subtítulo debe ser el ancla" (Simonetti, 2010: 279).

\subsection{El editor}

Villanueva Chang asegura que su labor de edición tiene un afán de explorar y descubrir acerca de nuevas parcelas de conocimiento: "De eso se trata al principio. De la curiosidad y de la atención como una posible forma de la inteligencia. Escribo sobre lo que no entiendo y cada uno de mis perfiles es, en ese sentido, un ensayo sobre mi propia ignorancia" (ibídem: 273). Esto tiene relación con la labor diaria del cronista, ya que este "trabaja con información que se sabe y que se ignora, pero en ambos casos que no se entiende" (Villanueva Chang, 2012: 585). El mencionado autor agrega:

"Un editor de periodismo narrativo es, en principio, un ignorante especialista en hacer buenas preguntas. Las frases que yo más uso con los autores con quienes trabajo son 'no sé' y 'no entiendo'. Este 'no sé' y 'no entiendo' es una vocación para que cualquier texto que aparezca en la revista sea consecuencia de un trabajo de reflexión entre el autor y el editor, esto es, sobre las ideas que se quieren decir en el texto, sobre el trabajo de archivo y de campo que tiene que hacer un cronista para luego sentarse a contar su historia, y finalmente sobre la aventura de escribir el texto en sí mismo, la artesanía, la arquitectura, o el estilo, como quiera llamarse. El objetivo obvio de este intercambio entre autor y editor son los lectores" (ápud CAF y FOPI, 2006: 147).

En el siguiente extracto, Villanueva Chang concentra las principales funciones del editor:

"Uno tiene que buscar y seleccionar historias extraordinarias para ambos extremos [sindicatos del 'hombre común' y 'expertos']. Y tiene que conmover y gustar y dar qué pensar tanto a un erudito como a alguien 
que no le interese un tema, y que además ni siquiera le guste leer. Yo creo que ese es un reto para un editor. Un editor también es alguien que busca descubrir lo que quiere decir un autor y trata de que éste se sienta cómodo traduciéndolo a una voz personal. Pero un editor también es un seductor y un manipulador. Oscila entre el padre y el tirano. Uno no usa el mismo traje para todos sino que trata de buscar el traje que sea más justo a cada situación y a cada historia y a un autor. $\mathrm{Y}$ un editor puede ser un seductor o un manipulador en el sentido de que a veces obliga al autor a que escriba un texto no solamente para el lector sino en contra del lector. Un editor es, en última instancia, el otro responsable de la excelencia o la mediocridad de un texto. Y es el primero en saber que no todo lo que publica es bueno" (ibídem: 148).

Villanueva Chang (2012: 605) sugiere que no existen "suficientes buenos cronistas, pero también hacen falta más editores que de vez en cuando apuesten por arriesgar con nuevos temas y modos de conocer mundos inaccesibles e ignorados". Tomar riesgos es parte ineludible del oficio del editor. Marco Avilés y Daniel Titinger (2009) rememoran la labor que implicó la comisión de su primera crónica larga sobre la gaseosa Inca Kola, que apareció en el séptimo número de Etiqueta Negra:

"Sólo teníamos una semana y media para reportar y dos para escribir. Eso, cuando tu tema parece 'importante', se convierte en un problema. Peor cuando los editores te dicen: 'Queremos un texto de unas seis mil palabras'. Nosotros éramos reporteros de día a día de un periódico. El texto más grande que habíamos escrito en nuestras vidas tenía, como máximo, mil palabras. Y seguro que nos habíamos demorado un par de semanas en investigar y escribir. Ahora nos pedían seis mil. 'Y si da para más, escriban sin miedo', dijeron los editores. Nos habíamos reunido con los editores en un café del distrito de Miraflores, y empezamos a hacer cálculos en las servilletas: tres semanas y media para el deadline. ¿Acaso estaban chiflados?".

El propio Villanueva Chang narra el trabajo en conjunto que se realizó en tono a la investigación desarrollada por José Carlos Paredes, titulada "Las mentiras de un héroe oficial” (Etiqueta Negra, núm. 32), centrada en la figura de Antonio Ketín Vidal:

"Esta era la primera vez que Paredes escribía una historia así. Él es un reportero originalmente de la televisión y sin embargo no tenía esa soberbia de los reporteros de historias duras que a veces miran por encima del hombro a los periodistas que no trabajan sobre temas de corrupción y que creen que hacer periodismo narrativo es el triunfo de la estética sobre la ética" (ápud CAF y FOPI, 2006: 165).

El mencionado autor detalla que dos editores y un verificador de datos de la revista revisaron todo el texto, línea por línea. Esto duró tres noches y tres madrugadas: 
"A Carlos Paredes le preguntamos de dónde había sacado cada una de las frases del texto y a cada pregunta él sacaba un documento judicial o prendía el televisor y hacía correr un video donde había una declaración, o nos mostraba archivos de periódico donde estaba algo que él citaba, o cintas de audio, o su propia libreta de notas. Incluso tenía un acta notarial firmada por uno de los testigos del caso para que después no se fuera a retractar, porque se sabía que el general de la policía Ketín Vidal extorsionaba a quien lo denunciaba para que se retractase" (ibídem).

José Carlos Paredes rescata el despliegue y meticulosidad del editor de Etiqueta Negra:

"Para mí, como reportero de televisión, fue un reto grande la propuesta de escribir la historia del general Vidal, porque no se trataba de escribir la típica historia de una denuncia de corrupción, sino una historia universal, la historia de una mentira. Julio Villanueva me propuso convertir una noticia en una historia. Escribirla fue un trabajo de varios meses. De hecho tuve que reeducar mi proceso periodístico, aprender a ver desde otra óptica toda la información que había acumulado durante tres años sobre este personaje. Si bien la televisión es un medio de mucho impacto, a veces es efímero. Y, aunque el periodismo narrativo es un género poco común en Latinoamérica, sí te permite algo que la televisión no te da: la reflexión. Eso fue lo que hicimos y creo que gran parte de la responsabilidad, o irresponsabilidad, la tienen los editores de Etiqueta Negra, sobre todo Julio Villanueva" (ibídem: 166).

\subsection{Reescribir}

Siguiendo al caso anterior, José Carlos Paredes tuvo que reescribir tres veces su texto de cinco capítulos. Esta necesidad de reescribir los textos ocurre con mucha frecuencia en Etiqueta Negra. Cuando los autores piensan que terminaron la redacción, empieza una siguiente etapa de reescritura, con la finalidad de que el texto alcance su plenitud y brinde lo mejor (Budasoff, 2014).

A inicios del 2014, Etiqueta Negra (núm. 117) incluyó una antología de perfiles que habían sido publicados en los tres últimos años, acerca de diversas personalidades internacionales (Cristiano Ronaldo, Carlos Slim, Isabel Allende, Joseph Stiglitz, entre otros), lo cual dio la oportunidad a los editores a reelaborar partes enteras de dichas piezas.

\subsection{Una fórmula}

La mayoría de los textos de Etiqueta Negra son, desde la perspectiva de Villanueva Chang, la consecuencia de la reflexión entre el autor y el editor (ápud CAF y FOPI, 2006: 147). En ese sentido, el editor tiene una gran influencia en el producto final. Este estilo ha suscitado algunas críticas, como la de Luis Miranda: 
"En el caso peruano, con Etiqueta Negra tengo dos impresiones. La primera, que es un gran aporte al periodismo de los últimos años con temas distintos y textos bien escritos, pero por otra parte me parece que el trabajo de edición hace que los artículos se vuelvan más uniformes. Parece una tendencia pero a veces da la impresión de que en algunas revistas los editores quieren ser las estrellas" (ápud Ortiz, 2012).

Villanueva Chang (2014) replica y explica lo siguiente:

"Es absurdo criticar que tú tengas la fórmula. Los mejores proyectos tienen una fórmula. El F. C. Barcelona, el mejor equipo del mundo, tiene una fórmula. Es falso creer que algo siempre está naciendo y muriendo en cada numero. No, no es así. Hay una rutina en el pensar, en el elegir, en el hacer. Yo pienso que alguien que quiere publicar en Etiqueta Negra tiene que saber que está escribiendo para una revista que trabaja con códigos".

\subsection{El equipo}

Villanueva Chang agrega una serie de cualidades referidas al editor:

"Un editor tiene estilos y manías. Creo que las publicaciones que tienen una personalidad definida, que no se parecen tanto a otras, dependen mucho de cierta especie de dictador amable que es el director y los editores con los que trabaja" (ápud CAF y FOPI, 2006: 148).

Durante el 2014, siete personas integraron el personal directivo y operativo de Etiqueta Negra: Julio Villanueva Chang es el director fundador; Eliezer Budasoff, desde enero de 2014, editor adjunto; Stefanie Pareja y Juan Francisco Ugarte, editores asistentes; Lucía Chuquillanqui, responsable de las ilustraciones y las fotos; Roger Ramirez, trabajador gráfico y Christian Suarre, asistente. También hay editores asociados que no trabajan en la redacción en Lima: Daniel Alarcón (San Francisco), Diego Salazar (Lima), Leonardo Faccio (Barcelona) y Diego Fonseca (Washington). Este mismo equipo editó Etiqueta Verde, la hermana ambiental y trimestral de Etiqueta Negra.

La exigencia prima en la mayoría de las etapas de composición y edición de los contenidos. De acuerdo con Budasoff (2014), el personal que trabaja y colabora con la revista sabe de antemano que el trabajo es "muy arduo, muy largo, terriblemente exigente". Avilés (2014) añade que en Etiqueta Negra "hay una cultura de exigencia para los jóvenes que entran. Es una cosa muy militar. Esto para mí es bueno para formar el carácter de alguien que quiere hacer periodismo". En suma,

"es un trabajo que te permite aprender. Trabajar y aprender se vuelven una misma cosa. Julio [Villanueva Chang] es un tipo que esta todo el tiempo viajando, super inspirado y estimulado siempre. Exige, pero te explica el 
porqué te pide estas cosas. En el Perú no hay una cultura de editores que sean tan profesionales en el mejor sentido".

Pese a las dificultades económicas y al índice de rotación de su personal, Etiqueta Negra se mantiene en el mercado peruano con un prestigio que la diferencia del resto de publicaciones literarias y culturales. Asimismo, en el extranjero conserva su aura de originalidad, creatividad y excelencia literaria, así como en la presentación visual. La gradual difusión de sus textos a través del ciberespacio ayudará a consolidar su posición de vanguardia en el mundo hispanohablante.

\section{Fuentes consultadas}

Aguilar, M. (2010). “Alberto Fuguet: en fuga", pp. 159-171. En Aguilar, M. (ed.). Domadores de historia. Conversaciones con grandes cronistas de América Latina. Santiago de Chile: Universidad Finis Terrae, RIL Editores.

Avilés, M. (2014, marzo 10). Periodista y editor. Director de empresa de comunicaciones Cometa. Entrevista personal. Lima.

Avilés, M. y Titinger, D. (2009). "El imperio de la Inca”. Extraída el 24/VII/2015 desde http://lenguajeinformativoii.blogspot.com/

Budasoff, E. (2014, abril 11). Editor adjunto de revista Etiqueta Negra. Entrevista personal. Lima.

CAF y FNPI (2006, agosto 28-29). "El papel del editor en la búsqueda de la calidad periodística". Memorias del seminario realizado en Monterrey, México. Extraída el 24/ VII/2015 desde http://publicaciones.caf.com/media/1383/207.pdf

Etiqueta Negra, revista. Núms. 2, 32, 33 y 115. Lima: Iso Print.

Fuentes, B. (ed.) (2009). Historia de una mujer bomba y otras crónicas de América Latina. Santiago de Chile: UAI, Uqbar.

Guerriero, L.

(2012a). "Sobre algunas mentiras del periodismo", pp. 616-626. En Jaramillo Agudelo, D. (ed.). Antología de crónica latinoamericana actual. Madrid: Alfaguara. Extraída el 24/VII/2015 desde http://www.opinion.com.bo/opinion/ramona/2013/0512/suplementos. php?id $=735$

_(2012b, febrero 15). "La verdad y el estilo". Extraída el 11/IX/2012 desde http://cultura. elpa is.com/cultura/2012/02/15/actualidad/1329307919_560267.html

Jalil, G. (2010). "Leila Guerriero: sufrir y amar (y sufrir otra vez) la escritura”, pp. 35-43. En Aguilar, M. (ed.). Domadores de historia. Conversaciones con grandes cronistas de América Latina. Santiago de Chile: Universidad Finis Terrae, RIL Editores. 
Muñoz, B. (2012), “Notas desabotonadas”, pp. 627-631. En Jaramillo Agudelo, D. (ed.). Antología de crónica latinoamericana actual. Madrid: Alfaguara.

Ortiz, R. (2012, enero 31). "El pluma del Oso más marginal”. Extraída el 24/VII/2015 desde http://elcinceldeamado.blogspot.com/search/label/Entrevista $\% 20 a \% 20$ Luis $\% 20$ Miranda

Simonetti, M. (2010), “Julio Villanueva: envidiando a Mr. Chang”, pp. 269-282. En Aguilar, M. (ed.). Domadores de historia. Conversaciones con grandes cronistas de América Latina. Santiago de Chile: Universidad Finis Terrae, RIL Editores.

Villanueva Chang, J.

_(2014, febrero 27). Director fundador de revista Etiqueta Negra. Entrevista personal. Lima.

_(2012). “En que enciende la luz. ¿Qué significa escribir una crónica hoy?”, pp. 583-606. En Jaramillo Agudelo, D. (ed.) Antología de crónica latinoamericana actual. Madrid: Alfaguara.

Villoro, J. (2012), "La crónica, ornitorrinco de la prosa", pp. 577-582. En Jaramillo Agudelo, D. (ed.) Antología de crónica latinoamericana actual. Madrid: Alfaguara. 